\title{
STRATEGIES AND OUTCOMES OF BIM EDUCATION: ITALIAN EXPERIENCES
}

\author{
SOFIA AGOSTINELLI, FABRIZIO CUMO \& FRANCESCO RUPERTO \\ Department of Planning Design and Technology of Architecture, Sapienza University of Rome, Italy
}

\begin{abstract}
The growing need on the part of operators in the construction sector for expertise in digital management of construction information processes has been answered since 2015 in the first level master course called BIM Master, from the Department of Planning Design and Technology of Architecture of Sapienza University of Rome. The training course is now in its fifth edition, registering a growing number of students. It has evolved in terms of content delivery methods, and always provides opportunities for internships in client, designers and construction organizations, achieving significant results in terms of placement. The BIM Master is one of the most consolidated national experiences, and has been proposed since the first edition as a training opportunity that links the needs of the market and the expectations of students. It is configured as a project in continuous development that adapts itself year after year to the evolutionary dynamics of the digital construction market, also resulting from the recent national regulatory innovations (UNI 11337). The complexity of BIM training also increases in relation to the different nature and needs of the operators in the sector: owners; designers; builders; and managers, who lead the need for articulated training courses in relation to the role played in the construction supply chain. This paper critically examines, also on the basis of the results of past editions, the training experience of the BIM Master course of Sapienza University of Rome, analyzing the structure, examining the articulation of the main training modules, assessing the results produced by the students, measuring the critical points and, at the same time, identifying the drivers of greater effectiveness in the transfer of skills of a theme that lends itself to ambiguous interpretations at this history time by operators in the construction industry.
\end{abstract}

Keywords: Master BIM, BIM mandate, BIM education, BIM training, project management.

\section{INTRODUCTION}

The construction sector, such as all production sectors, is experiencing its "digital revolution"; the adoption of BIM methodologies represents the digitization of the construction sector, and is being rapidly developed by different components of the value chain, as a strategic tool that offers costs savings, productive and operative efficiency and better infrastructure quality and environmental performance.

The transition of an entire industrial sector from analogical to digital and computational production methods cannot be considered only as a translation of physical quantities, but also as a cultural transformation, which requires a deep rethinking of the practices in all the disciplines of the construction industry and the related design, production, management and building/city use processes.

This is a complex challenge that the EU BIM Task Group (EUBIMTG), supported by the European Commission, is leading at a community level, having recently won the first ever European BIM Summit Award for its work on a common framework for a large-scale introduction and provision of a definition of BIM for the public sector in Europe.

As a result, on 6 July 2017 the document Handbook for the Introduction of BIM by Europe's Public Sector was published by the EU BIM Task Group, which is a pan-European collaboration that gathers public sector expertise from infrastructure to owners, public customers and policy-makers of 21 nations. This publication is significantly important to direct the industrial policies of the European community member countries and prevent a 
disorganized proceeding towards the introduction of BIM, which inevitably create the premises for a fragmentation of the continental construction market [1].

In Italy the Infrastructure and Transport Ministry Decree (560/2017) [2] outlines the national strategy for the progressive compulsory adoption of electronic modeling methods and tools in the public sector, and reflects what was already introduced in the art. 23 c. 13 of Legislative Decree 50/2016 [3]; it focuses on the topic of training as the preliminary requirements of the contracting authorities that insert digital information requirements in the project specifications. Therefore, even the national legislator, by directing its organizations to a conscious use of what is made available by technology, recognizes the training of specific skills as a moment of growth essential to achieve the objectives: enhancement of public spending and efficiency of the supply chain.

The challenge of the construction sector digitization was also taken up by the postgraduate training system of Italian universities with the instrument of I and II level University Masters [4]. It has been experimented for the first time in Rome and Milan, and over the years also in Naples, Pisa, Ferrara, Turin, Reggio Calabria, Genoa and other universities. This article is an illustration of experiences and results from the BIM Master course of Sapienza University of Rome, active since 2014 (as those of Politecnico and Scuola Pesenti of Milan).

To these academic experiences have been added those of the technical professions representatives such as CNI (National Council of Engineers), CNAPPC (National Council of Architects, Landscape and Conservation Planners), ANCE (National Association of Building Constructors), FORMEDIL (national body for training and professional training in construction) with actions throughout the national territory.

As an evidence of this training effort it can be cited the recent experience of CNAPPC, which has developed a short guide entitled "BIM Bang", an introduction to BIM and digital revolution of built environment, that could allow Italian architects to have a greater awareness on the current changes [5]. The ANCE project is also part of these actions based on increasing the awareness and training of associated companies throughout the country in the BIM field with a specially designed training course. Then, another example of such experiences is conducted by the building schools of FORMEDIL network [6], also in collaboration with ITS technical institutes (schools for applied technologies), Post Diploma Technical Specialization courses, referred to areas considered to be priorities for economic development and country's competitiveness, carried out in collaboration with companies, universities/scientific and technological research centers, local authorities, education and training system.

\section{BETWEEN ROLES, FUNCTIONS AND COMPETENCES}

In the international and national scene, BIM methodologies and tools are increasingly subjected to regulations so that roles, functions and skills useful to operators in the digital construction sector are gradually being defined [19].

At international level was recently published the ISO 19650 standard [7], concerning the "Organization and digitization of information on buildings and civil engineering works, including Building Information Modeling" (ISO 19650-1/2), which in the specific ISO 19650-1 at point 7, investigates the functions related to project and asset information management [5].

At a national level, part 7 of the UNI 11337 [8], [14] standard defines the "Requirements related to the professional activity of the involved figures, in management and information modelling" (UNI 11337-7). For the Italian digital construction sector this standard, published in December 2018 and managed by the "Products, processes and systems for the building 
organization" commission, represents a big step towards the digitization of designing, building management processes, defining the requirements related to the professional activity of the following figures:

- Common data environment manager (CDE manager);

- Manager of digital processes (BIM manager);

- Coordinator of the information flow (BIM coordinator);

- Advanced information management and modeling operator (BIM specialist).

UNI 11337-7 defines the requirements of knowledge, skills and competence of the figures involved in the management and information modeling. These are useful to the organizations' need to get qualified staff, or to train and update their internal resources. This need unites all the protagonists of the construction supply chain who want to introduce BIM in their organizations (designer, builders, providers of maintenance and facility management services etc.) and is also linked to the continuous growth, in national and international projects, of specifications related to digital information management [6].

These requirements are identified and divided in specific tasks and activities carried out by professionals in terms of "knowledge, skills and competence" according to the European Qualifications Framework (EDF) [9]. It is important to note that for each figure identified, the standard describes specific tasks and activities in the information flow which are also related to the organizations where they are required to operate, without making any reference to specific study background. Below are indicated the requirements of knowledge, skills and competence that must be possessed from each figure to pursue the identified objectives.

\subsection{CDE manager}

The CDE manager can be placed at a "client level", managing an "overall" CDE of the contracting authority at an organization level related to more interventions, or even to the single project. He control and monitors tasks in the interoperable information process, relating the contents of the models with other data present on the platform and verifying the correctness and timeliness of the information flow by applying, if necessary, the appropriate data protection measures; therefore it is required a base knowledge of the main IT systems, and in particular of networks and cloud infrastructures, as well as of cyber-security and dataanalytics principles, project management and information exchange protocols.

\subsection{BIM manager}

Even in the BIM manager case, he can be a figure linked to the organization, defined as "BIM manager company", or at a project level. This figure deals with project management and coordination, collaborating directly with the BIM coordinators named by him, with a processapproach. The BIM manager deals with the organization's digital processes, for example defining and progressively updating the guidelines relating to internal procedures, as well as other documentation such as specifications and tender documents (e.g. BIM execution plan), then defining the contractual aspects and carrying out audit analysis.

The essential technical knowledge required to him is related to the main engineering processes and the ability to manage IT flows by applying quality management systems and conducting audits. He also needs to be aware of cyber security and project management principles, as well as of the main operative software applications used in the project. 


\subsection{BIM coordinator}

The BIM coordinator works at the level of a single project as the first figure called to be coordinate the modelling activities. Therefore he can be a technician able to manage information models with competence and coordinate the activities of BIM specialists. Then he personally coordinates the digital processes of the organization, evaluating and managing the interferences and conflicts and finally validating the models. Such as the BIM manager he needs skills in the areas of project management, IT management and cyber security systems, focusing on information exchange protocols, model and quality level management and engineering processes related to the project.

\subsection{BIM specialist}

The BIM specialist works at a level of the individual project and often coincides with a figure of junior technician specialized in a specific disciplinary field. He introduces its technical abilities within the information model using specific applications and according to the contractual documentation and the operational guidelines. His knowledge coincides with the BIM coordinator's, but in a purely operational context of software tools used for the realization of the model, for all of its specific uses and possible implementations.

\section{THE EXPERIENCE OF "MASTER BIM"}

In this rapidly evolving context, the BIM Master course of Sapienza University of Rome [10], promoted by the Faculty of Architecture and organized by the PDTA (Department of Planning, Design, Technology of Architecture) already responds to the growing need of training of new professional figures dedicated to the integrated management of information related to buildings life cycle, following the European Directive procurement reform (2014/24/EU) [11]. The partners of the BIM Master include category associations such as ACER (ANCE of Rome), FORMEDIL (National Agency for Training and Vocational Training in Building) as well as specific companies in the construction sector.

The Master course, directed by Fabrizio Cumo, is part of the training courses offered by PDTA, it originates from the experience carried out since 2010, in the Project Management Degree course and is a consistent part of the annual workshop promoted by the Department of History, Design and Restoration of Architecture (DSDRA) 3D Modeling and BIM [12].

Since from the first edition, this Master course has taken on the need to develop specialist skills in BIM towards a varied body of students, made up of young graduates from the faculties of architecture and engineering, and also older people enrolled in professional associations, with the aim to facilitate their professional integration into the national and international construction market. In fact, many of the older students are interested in redevelop their skills, still required by lot of Italian companies that have to implement new business processes to compete on international markets. As a result, the experience of the BIM Master combines the actual need of expert and specialized figures on BIM issues, with the expectations of members who usually are driven by the need to upgrade their personal skills, thus making them more attractive on the construction market [13].

\section{ORGANISATION OF EDUCATION SYSTEMS}

The BIM education of BIM Master is aimed at acquiring knowledge on the opportunities and advantages deriving from the organization of workflows based on ICT (BIM) that allow an integrated management of processes oriented towards a renewed digitized scenario of the construction industry [15]. During the front-end teaching, companies and professionals 
already operating in the BIM field make extensive testimonial sessions in order to promote the growth of a mature and aware competence in digital construction practices, that goes beyond the instrumental aspects and provides concreteness and tangibility to the quality of teaching.

The supervisory bodies and address of the training course is composed of a didacticscientific council supported by a technical group, also in order to better intercept the requests coming from the market scenarios that the candidates intend to correspond. The Master course uses specific conventions as well as teaching and technical partners, which transfer to the students a qualified methodological and instrumental contextualization, referring to real case studies. Moreover, according to the university impartiality about technical instruments utilization, the main suppliers of digital technologies for construction and infrastructure cooperate with the BIM Master in the form of teaching software partner and training sponsor.

The structuring of the competences delivered by the Master course about the digital management methods of the information processes in the construction industry, is organized according to a horizontal guideline, which every student verticalize depending on their specific professional choices and interests during the internship, and which they consolidate developing the thesis that is a synthesis of their activities.

The training is set up with a multidisciplinary approach and conducted by a team composed of university professors, external experts and researchers, according to two main lines: BIM education and BIM training.

Classroom teaching is organized in a total of 300 hours:

- 100 hours of BIM training on modeling platforms and 4D/5D instruments;

- 200 hours of BIM education about methods, regulations and case studies.

During the teaching activity it is also planned to carry out some exercises based on "role playing" and organized by groups, aimed at experimenting with the principles, methods and tools that are object of the education. These exercises enable the students to concretely face the complexities of a BIM process, simulating the development of a specific digital information management process, based on sharing and collaboration, starting from its planning, up to the achievement of the objectives. At the end of the lectures, the students are involved in a 325 hour curricular internship, which is mandatory for the final thesis that effectively represents the synthesis of their education path, as well as a moment of reflection and sharing their experience.

\section{ACHIEVEMENTS AND STATISTICS}

Considering the last editions (2016, 2017 and 2018) of the BIM Master course, coordinated by Francesco Ruperto, and analyzing the population of the students, it is possible to distinguish a part of members made up of young graduates between 25 and 35 years old, and another one between 35 and 55. Both the age groups are interested in directing their professionalism towards the digital construction sector, acquiring competence in the use of advanced technological platforms and tools, but also getting the necessary knowledge to manage the complexity of the transition taking place in the construction field.

Below are some statistical data derived from a critical analysis of the last BIM Master's editions, ranging from 2016 to 2018, for a total of three editions attended by 71 students. Some of them were already active at a professional level and attributable to planning, construction and public structures.

The first analysis, shown below in Fig. 1, distinguishes the population of students by their previous qualification (degree of entry) finding four main categories: 
1. Senior architects;

2. Senior engineers;

3. Junior architects;

4. Junior engineers.

Senior are defined as the Master graduates in architecture and building or civil engineering, (even already employed), and junior are the three-year graduates with particular interest for the BIM field.

Fig. 2 shows how the design companies represent the most of active bodies in the implementation of BIM methodologies. In fact, $55 \%$ of the students carried out their internship and professional experience within a design team. These structures are confirmed to be the most interested in collaborating with universities, since it is established a relationship of mutual exchange that, both enhances their structures hosting technical and specialized figures, and offers them a valuable opportunity for personal and professional growth. Therefore, as already represented above in Fig. 1, the audience of the Master BIM has always been characterized by a considerable heterogeneity of the origins in terms of previous qualifications, experience and prospects of students and, as shown in Fig. 2, the host organizations are representative of different categories.

In Fig. 3 we analyze instead the distribution of students based on their qualifications within the various organizations hosting the internships divided by categories: owner, designer, constructor and researcher.

In Fig. 3 it can be noticed the category of owners (representing client organizations) and designers (who represent design companies) favored junior architects (59\% and 51\%) while construction companies and research organisation mainly hosted senior architects (46 and $40 \%$ ) as shown in Figs 3(c) and (d).

Fig. 4, on the other hand, concerns the percentage distribution by qualification through the three last editions of the Master course within the specific host organisations.

Ultimately, architects are the most required by design companies, while engineers are most involved in construction companies and owners.

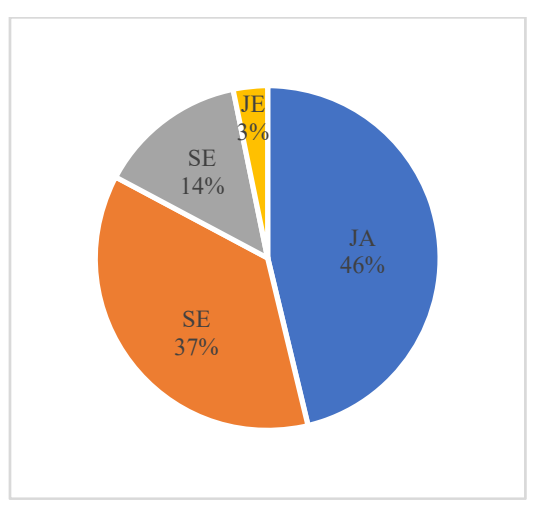

Figure 1: Students' entry qualifications. $\mathrm{JA}=$ Junior architects; $\mathrm{SA}=$ Senior architects; JE = Junior engineer; and $\mathrm{SE}=$ Senior engineer.

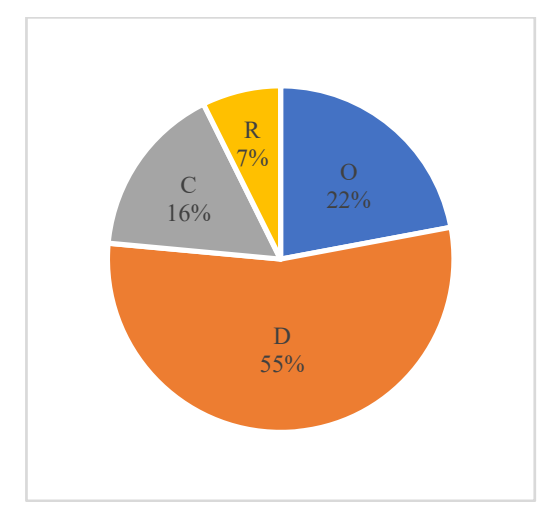

Figure 2: Placement distribution by type of host organizations. $\mathrm{D}=$ Designer; $\mathrm{O}=$ Owner; $\mathrm{C}=$ Constructor; and $\mathrm{R}=$ Researcher. 


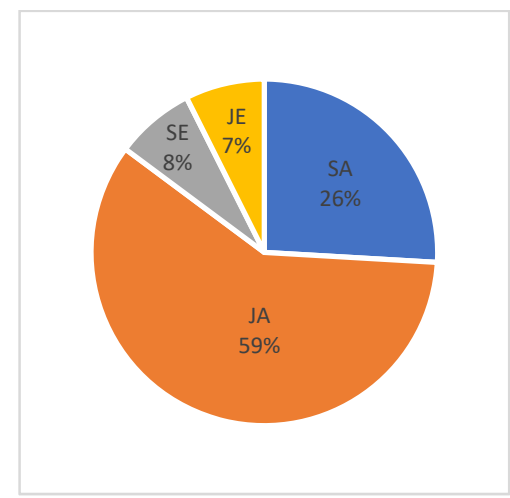

(a)

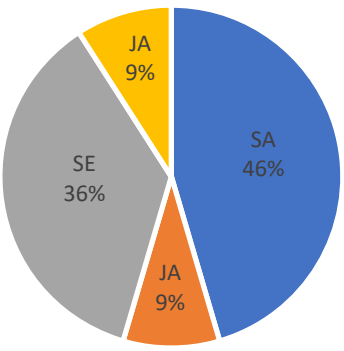

(c)

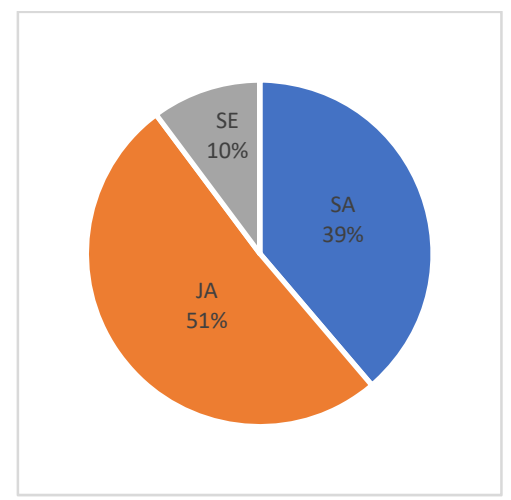

(b)

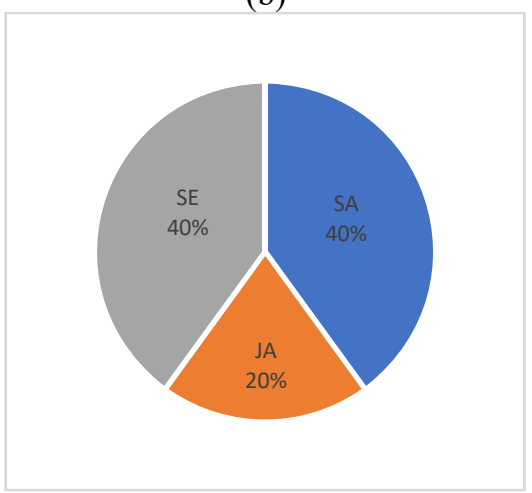

(d)

Figure 3: (a) Owner; (b) Designer; (c) Constructor; and (d) Researcher. JA = Junior architects; $\mathrm{SA}=$ Senior architects; $\mathrm{JE}=$ Junior engineer; and $\mathrm{SE}=$ Senior engineer.

Therefore, it was carried out an analysis based on the individual experiences of the students during their internship. Through this analysis it was possible to classify the activities carried out and based on the general model uses (GMU) and domain model uses (DMU) (codified by the BIMe initiative) [16], [17] respectively represented by categories of general model uses applicable across industries, information systems and knowledge domains (e.g. architectural modeling, conservation modelling, etc.) and those industry-specific (e.g. capturing and representing, planning and designing, etc.). Each experience was assigned a sample of three GMU and DMU, so that it was possible to summarize their distribution and identify the most frequents.

From the analysis concerning the type of BIM approach during the internships resulted a reflection about the types of intervention considered, dividing them in two typologies: new construction interventions and those on the existing and, as shown in Fig. 6, the distribution of students is roughly equivalent in these terms [18].

Furthermore, a clear majority operated in the field of the so-called vertical BIM (Fig. 7) represented by the digital modeling of buildings or objects considered as punctual, while a minority on the horizontal BIM which expresses the "linear" interventions (e.g. infrastructures, metro lines, etc.). 


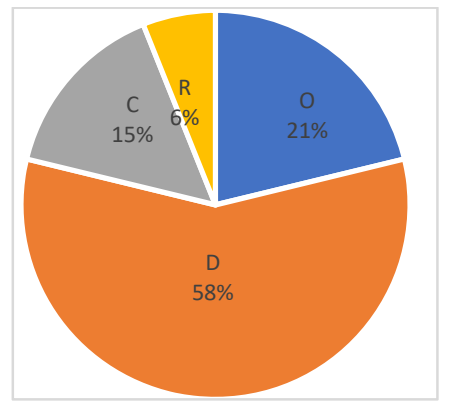

(a)

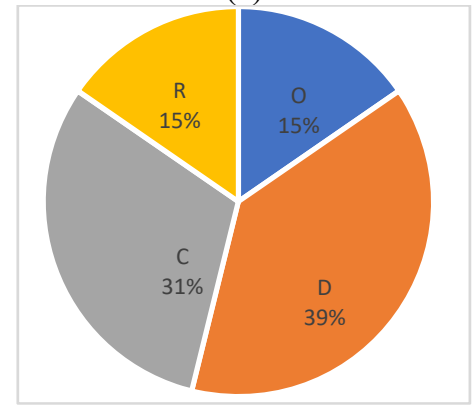

(c)

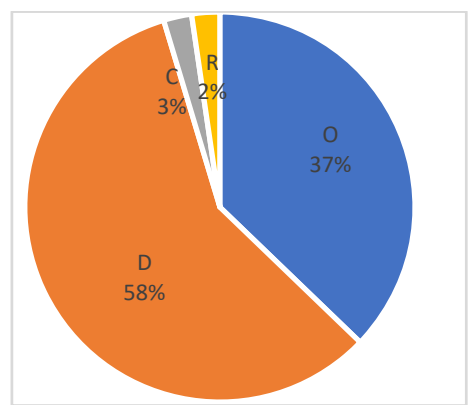

(b)

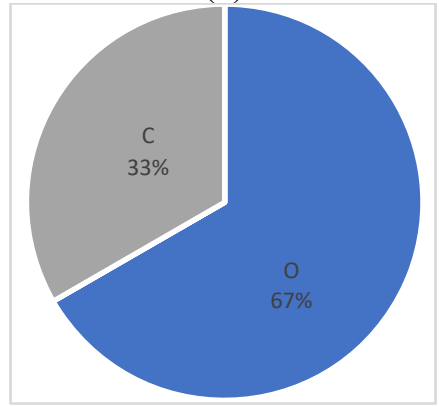

(d)

Figure 4: (a) Architects; (b) Junior architects; (c) Engineer; and (d) Junior Engineer. D = Designer; $\mathrm{O}=$ Owner; $\mathrm{C}=$ Constructor: and $\mathrm{R}=$ Researcher.

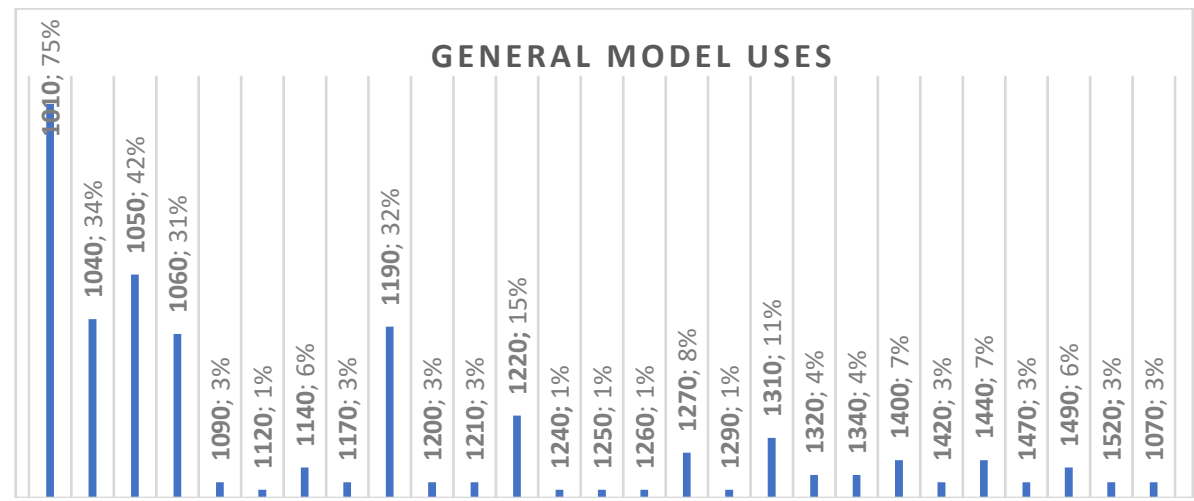

Key: 1010 Architectural Modelling; 1040 Brick Structures Modelling; 1050 Concrete Structures Modelling; 1060 Conservation Modelling; 1070 Decorative Modelling; 1090 Drainage Systems Modelling; 1120 Façade Systems Modelling; 1140 Fitout Modelling; 1170 Foundations Modelling; 1190 HVAC Systems Modelling; 1200 Hydraulic Systems Modelling; 1210 Information Systems Modelling; 1220 Infrastructure Systems Modelling; 1240 Landscape Modelling; 1250 Lighting Systems Modelling; 1260 Marine Structures Modelling; 1270 Masonry Structures Modelling; 1290 Modular Units Modelling; 1310 Parametric Modelling; 1320 Power Systems Modelling; 1340 Renovation Modelling; 1400 Steel Frame Modelling; 1470 Transportation Systems Modelling; 1490 Urban Modelling; 1520 Wood Frame Modelling [8].

(a)

Figure 5: (a) Students' placement analysis based on GMU; and (b) Students' placement analysis based on DMU. 


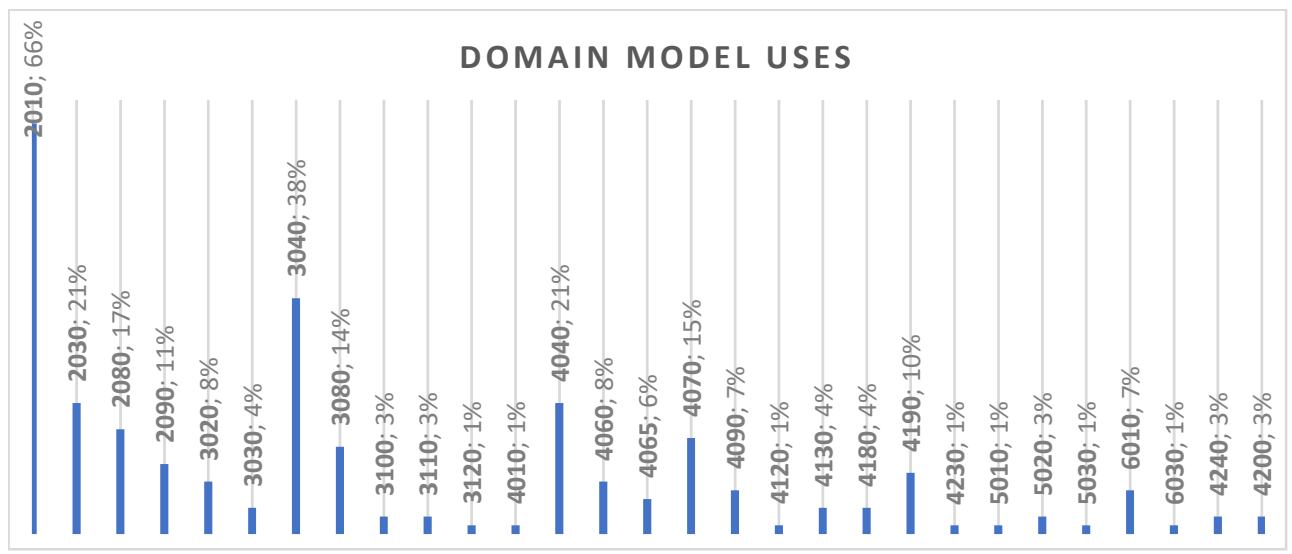

Key: Capturing and Representing: 2010 2D Documentation; 2030 As-constructed Representation; 2080 Surveying; 2090 Visual Communication. Planning and Designing: 3020 Construction Planning; 3030 Demolition Planning; 3040 Design Authoring; 3080 Operations Planning; 3100 Space Programming; 3110 Urban Planning;

3120 Value Analysis Simulating and Quantifying: 4010 Accessibility Analysis; 4040 Clash Detection; 4060 Constructability Analysis; 4065 Construction Operation Analysis; 4070 Cost Estimation; 4090 Energy Utilisation; 4120 Lighting Analysis; 4130 Quantity Take-off; 4180 Site Analysis; 4190 Solar Analysis; 4230 Thermal Analysis; Constructing and Fabricating: 5010 3D Printing; 5020 Architectural Modules Prefabrication; 5030 Casework Prefabrication; Operating and Maintaining: 6010 Asset Maintenance; 6030 Asset Tracking [8].

(b)

Figure 5: Continued.

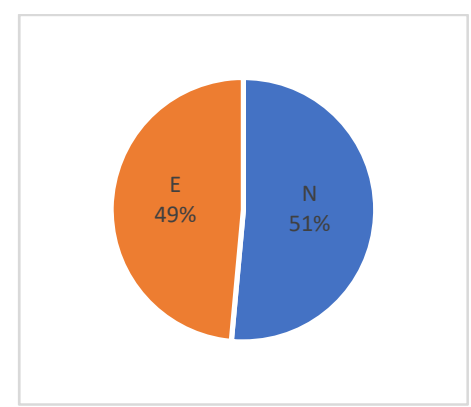

Figure 6: New construction (N)/existing facilities $(\mathrm{E})$.

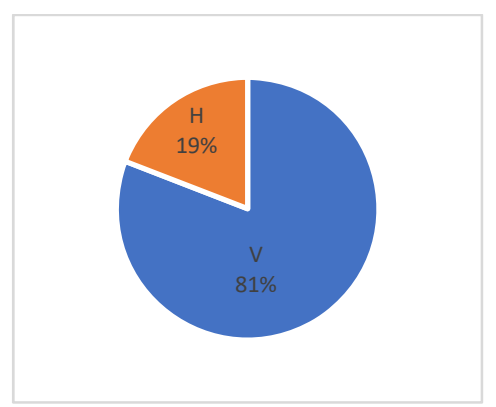

Figure 7: Vertical (V)/horizontal (H) BIM.

\section{CONCLUSIONS}

The first four editions of the BIM Master course have achieved increasing levels of success in terms of skills, internships and placements of graduates. These results, although in the analytical phase, are today based on the informal return of information, deriving from a virtuous chain that is activated between graduates placed in the organizations and aspiring trainees of the following editions.

From the statistical analysis conducted on the students of the 2016, 2017 and 2018 BIM Master editions, it becomes evident the peculiar nature of the course, which is characterized 
by the choice to provide contents aimed at BIM-based project management without considering students' qualifications or the category of organization they belong to.

The internship activities conducted by the students in the operative organizations where they are involved allow them to consolidate and test the skills acquired on methods and tools of information modeling in real project cases. This also avoids the risk of giving only theoretical lessons, making possible methodological-instrumental trainings, reinforcing the reasons for a greater interaction between university and operations. Such dynamics and evidences are also useful as they contribute to the process of continuous improvement of the contents of the Master course, but also allow a privileged reading of the construction field needs on a transversal and evolutionary theme such as BIM.

The fifth edition of the BIM Master (2019) confirmed the growing trend of interest with about 60 applications coming from young graduates, professionals motivated by the updating of their skills, and technical staff of the public administration. There is also a considerable interest from public organisations (that are gradually joining BIM-based processes) in the activation of agreements aimed at curricular internships.

\section{ACKNOWLEDGEMENTS}

The authors would like to thank the following professionals and professors for their contribution to BIM Master results: Stefano Amista, Pietro Baratono, Alfred De Pascali, Alberto Pavan, Livio Sacchi, Valeria Zacchei.

\section{REFERENCES}

[1] EUBIM Task Group, Handbook for the Introduction of Building Information Modelling by the European Public Sector. Strategic Action for Construction Sector Performance: Driving Value, Innovation and Growth, p. 78, 2017.

[2] Ministero Infrastrutture e Trasporti, Decreto Ministeriale n. 560 del 1 December 2017, Official Gazette of the Italian Republic, 2017.

[3] President of the Italian Republic, Article 23, paragraph 13, of Legislative Decree No 50 of 18 April 2016 on the implementation of Directives 2014/23/EU, 2014/24/EU and $2014 / 25 / \mathrm{EU}$ on the award of concession contracts, public contracts and the procurement procedures of entities operating in the water, energy, transport and postal services sectors and on the reorganisation of the rules in force on public contracts relating to works, services and supplies, Official Gazette of the Italian Republic, 2016.

[4] Ministry of Education, University and Research. 1st and 2nd level Master's degrees. https://miur.gov.it/master-universitari-di-1-e-2-livello. Accessed on: 20 Jul. 2019.

[5] Alesi, U., Aimetti, M., Melchini, T. \& Ruperto, F., BIM BANG. Breve introduzione all'era digitale del mondo delle costruzioni, National Council of Architects and Planners, 2019.

[6] ITS Higher Technical Institutes - Schools for Applied Technologies, Ministry of Education, University and Research. www.sistemaits.it/index.php. Accessed on: 27 Jul. 2019.

[7] International Organization for Standardization, ISO 19650:2018: Organization and digitization of information about buildings and civil engineering works, including building information modelling (BIM) - Information management using building information modelling, 2018.

[8] National Standards Institute, UNI 11337:2017: Construction and civil engineering works - Digital management of construction information processes, Milan, 2017.

[9] European Qualification Framework, www.isfol.it/eqf. Accessed on: 20 Jul. 2019. 
[10] Sapienza Università di Roma, Master BIM. https://web.uniroma1.it/masterbim/. Accessed on: 20 Jul. 2019.

[11] Directive 2014/24/EU of the European Parliament and of the Council of 26 February 2014 on public procurement and repealing Directive 2004/18/EC, Official Journal of the European Union, 2014.

[12] Empler, T., Quici, F. \& Ruperto, F., Workshop 3D Modeling and BIM, Sapienza Università di Roma. www.3d-modeling.it/it/home/. Accessed on: 20 Jul. 2019.

[13] Russo Ermolli, S., The Changing Architect. Innovazione Tecnologica e Modellazione Informativa per L'efficienza dei Processi, Maggioli Editore, pp. 31-77, 2018.

[14] Pavan, A., Mirarchi, C. \& Giani, M., BIM: Metodi e Strumenti-Progettare, Costruire e Gestire Nell'era Digitale, Tecniche Nuove, 2018.

[15] Ciribini, A.L., BIM e Digitalizzazione Dell'ambiente Costruito, Grafill, 2018.

[16] BIMe, Model uses table. https://bimexcellence.org/wp-content/uploads/211in-ModelUses-Table.pdf. Accessed on: 20 Jul. 2019.

[17] Computer Integrated Construction Research Group at Penn State, BIM uses, 2013. www.bim.psu.edu/bim_uses/.

[18] Valentini, S. \& Ruperto, F., BIM FM-Oriented, FMI - Facility Management, Italy.

[19] Ruperto, F. \& Zacchei, V., Sezione BIM, Nuovissimo Manuale dell'Architetto, vol. 3, Mancosu Editore: Rome, 2019. 